\title{
Osteopetrosis with renal tubular acidosis
}

INSERM

\section{Source}

INSERM. (1999). Orphanet: an online rare disease and orphan drug data base.

Osteopetrosis with renal tubular acidosis. ORPHA:2785

Osteopetrosis with renal tubular acidosis is a rare disorder characterized by osteopetrosis (see this term), renal tubular acidosis (RTA), and neurological disorders related to cerebral calcifications. 